\title{
Adverse Drug Reaction Reporting: Opportunities to Increase Pharmacists' Role
}

\author{
Stephen Shalansky
}

$\mathrm{T}$ his issue of the Canadian Journal of Hospital Pharmacy $(C J H P)$ includes 2 articles that concern adverse drug reactions (ADRs). Roy and $\mathrm{Ma}^{1}$ report on the impact of a policy change on pharmacists' reporting of ADRs, while Auyeung and Lee $^{2}$ provide a case report of Stevens-Johnson syndrome associated with ciprofloxacin use. Over the past several decades, the CJHP has published numerous articles describing pharmacists' involvement in ADR reporting and treatment, as well as the incidence of adverse drug events. This long-term, continuing focus on ADR reporting in the $C J H P$ is a good prompt for all of us who work as pharmacists to re-evaluate our current perspectives on this topic and to become aware of new opportunities to increase pharmacists' role in this important responsibility.

$\mathrm{ADR}$ monitoring is key to drug regulation processes around the world, and pharmacists play an integral role in drug safety in all practice settings. ${ }^{2,3}$ The day-to-day role of clinical pharmacists in hospitals is particularly well suited for identifying and reporting ADRs. In the context of its Therapeutics Access Strategy, Health Canada operates the MedEffect Canada program, with the intent of centralizing and simplifying ADR reporting. ${ }^{4}$ Faculties of pharmacy across Canada teach students about the goals and importance of ADR reporting, and clinical rotations often include components of the ADR reporting process among their required activities. Despite the emphasis on ADR reporting in pharmacy education and hospital pharmacy practice, the frequency of reporting remains suboptimal, with pharmacists being responsible for only $10 \%$ of all ADR reports submitted to Health Canada in 2012. ${ }^{1,5}$ What can we, as pharmacy practitioners, do to improve the uptake of this fundamentally important responsibility?

First and foremost, we can become familiar with the current Canadian ADR reporting process, and be role models the next time any of us encounters a reportable ADR. With implementation of entry-to-practice PharmD programs across Canada and the resulting increase in the number of student rotations in hospitals, there is ample opportunity to involve students in the
MedEffect Canada program. In a recent study, Wentzell and others ${ }^{6}$ showed that the availability of pharmacy students to facilitate ADR reporting helped to offset pharmacists' workload associated with this activity, and increased the frequency of ADR reporting. Furthermore, the students strongly agreed

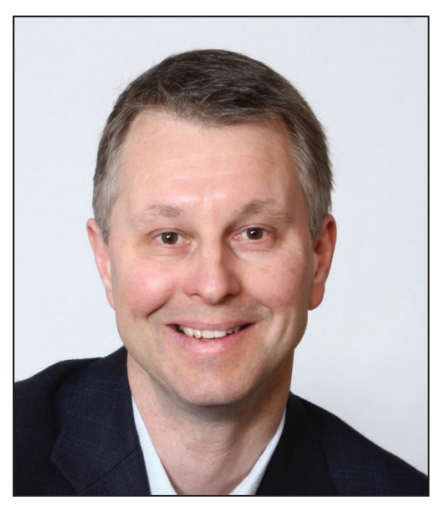
that the responsibility for reporting ADRs should remain with pharmacy students during future rotations.

The proposed amendments to the Food and Drug Regulations that would require hospitals to report serious ADRs, published in June 2018 in the Canada Gazette, Part $I^{7}$ create incentive to be more proactive about $\mathrm{ADR}$ reporting. Once you have worked through one ADR report for Health Canada, it will be much easier the next time, and you can start to build momentum. Teach your students about ADR reporting when on rotation and even during didactic lectures. Hold a journal club about the MedEffect Canada program, even if you don't have a case example immediately on hand. Also, be sure to educate your patients about medication safety principles, including ADR reporting, particularly for patients who have previously experienced an ADR. It is important to keep in mind that patients can report ADRs directly to Health Canada through the same process as pharmacists use.

Case reports are a constructive mechanism for sharing valuable information about ADRs, and an excellent way to start or build on your publication experience. In my own very first publication (which happens to have appeared in $C J H P$ ), ${ }^{8} \mathrm{I}$ reported on an ADR resulting from a drug interaction, and I know several other clinical pharmacists whose first publication 
involved a case report of an ADR. Roy and $\mathrm{Ma}^{1}$ have gone a step further by publishing a description of how they implemented a policy change to reinforce and streamline the ADR reporting requirements at their institution's outpatient clinics. Of course, ADR reporting is the responsibility of all members of the health care team, and it is also a key component of Accreditation Canada's Medication Management Standards — a good reminder that such reporting is not considered optional by the accreditors. ${ }^{9}$

Large-scale studies in both Canada and the United States have demonstrated that adverse drug events are both common and often preventable. ${ }^{10,11}$ ADR reporting has resulted in many important changes to drug labelling, the publication of safety alerts, and even the withdrawal of specific products from the Canadian market. ${ }^{12}$ ADR reporting does take time, but the impact it can have on patient care and medication safety is clearly worth the small effort it takes up front.

When faced with an ADR in your clinical practice, keep your patients in mind. There is undoubtedly a time when you have made a therapeutic recommendation or performed an intervention in which information about a previously reported ADR played a vital role. Help ensure that pharmacists faced with similar situations in the future have as much information as possible to make the best therapeutic interventions for the unfortunate patients who have experienced an ADR or are at risk of a future ADR. Collectively, we can help improve patient and product safety, as well as enhancing Canadians' knowledge to ensure they can make the best choices possible about their medication regimens.

\section{References}

1. Roy R, Ma J. Impact of a policy change on pharmacists' reporting of adverse drug reactions. Can J Hosp Pharm. 2018;71(4):227-33

2. Auyeung J, Lee M. Successful treatment of Stevens-Johnson syndrome with cyclosporine and corticosteroid. Can J Hosp Pharm. 2018;71(4):272-5.

3. Generali JA. Adverse drug event reporting: awareness is not enough. Hosp Pharm. 2014;49(2):110-1.

4. About MedEffect Canada. Ottawa (ON): Health Canada; [cited 2018 Apr 5]. Available from: https:/www.canada.ca/en/health-canada/services/ drugs-health-products/medeffect-canada/medeffect-canada.html

5. McMorran M, McEnaney J. Adverse reaction and incident reporting2012. Can Adverse React Newsl. 2013 [cited 2018 Apr 5];23(3):2-5. Available from: www.hc-sc.gc.ca/dhp-mps/alt_formats/pdf/medeff/bulletin/carn-bcei_ v23n3-eng.pdf
6. Wentzell J, Nguyen T, Bui S, MacDonald E. Pharmacy student facilitation of reporting of adverse drug reactions in a hospital. Can J Hosp Pharm. 2017;70(4):276-80.

7. Regulations amending the Food and Drug Regulations (serious adverse drug reaction reporting - hospitals). Can Gazette Pt I. 2018 Jun 16 [cited 2018 Aug 15];152(24). Available from: www.gazette.gc.ca/rp-pr/p1/2018/ 2018-06-16/html/reg5-eng.html

8. Landsberg KF, Shalansky SJ. Interaction between phenytoin and theophylline. Can J Hosp Pharm. 1988;41(1):31-2.

9. Standards: medication management standards for surveys starting after: January 1, 2018. Version 12. Ottawa (ON): Accreditation Canada.

10. Baker GR, Norton PG, Flintoft V, Blais R, Brown A, Cox J, et al. The Canadian Adverse Event Study: the incidence of adverse events among hospital patients in Canada. CMAJ. 2004;170(11):1678-86.

11. Bates DW, Cullen DJ, Laird N, Petersen LA, Small SD, Servi D, et al.; ADE Prevention Study Group. Incidence of adverse drug events and potential adverse drug events. Implications for prevention. JAMA. 1995;274(1):29-34.

12. Wiktorowicz ME, Lexchin J, Moscou K, Silversides A, Eggertson L. Keeping an eye on prescription drugs, keeping Canadians safe. Active monitoring systems for drug safety and effectiveness in Canada and internationally. Toronto (ON): Health Council of Canada; 2010 Nov [cited 2018 Aril 4]. Available from: http://publications.gc.ca/collections/collection_2011/ccs-hcc/H174-212010-eng.pdf

Stephen Shalansky, BSC(Pharm), PharmD, ACPR, FCSHP, is the Clinical Coordinator of the Pharmacy Department, Providence Health Care, and is a Clinical Professor in the Faculty of Pharmaceutical Sciences, The University of British Columbia, Vancouver, British Columbia. He is also the Editor of the Canadian Journal of Hospital Pharmacy.

Competing interests: None declared.

Address correspondence to:

Dr Stephen Shalansky

Pharmacy Department

Providence Health Care

1081 Burrard Street

Vancouver BC V6Z 1 Y6

e-mail: sshalansky@providencehealth.bc.ca 